\title{
Case - Prostatic abscess in an adolescent
}

\author{
Tze-Chen Chao; Stephen Shei-Dei Yang
}

Division of Urology, Taipei Tzu Chi Hospital, the Buddhist Tzu Chi Medical Foundation; School of Medicine, Budhist Tzu Chi University, Hualien, Taiwan

Cite as: Can Urol Assoc J 2018 November 20; Epub ahead of print. http://dx.doi.org/10.5489/cuaj.5542

Published online November 20, 2018

\section{Introduction}

Prostatic abscess is uncommon in adults and is infrequently noted in the pediatric population. The current recommended management for prostatic abscess larger than $1 \mathrm{~cm}$ is surgical drainage with adequate antibiotics. ${ }^{[1]}$ However, the appropriate management of a prostatic abscess remains under debate. Herein, we present the case of an case with a large prostate abscess and without a systemic disease who was successfully treated with antibiotics only and did not require surgical drainage.

\section{Case report}

A 14-year-old adolescent male who presented with fever and low back pain for one week was transferred to our hospital. Urine culture at a previous hospital revealed the presence of Escherichia coli, which was resistant to the fourth generation of cephalosporin and fluoroquinolone. The patient denied a history of recent trauma, bladder or bowel symptoms, drug allergy, drug abuse, and any sexual or travel history. At the age of 4 years, he underwent hypospadias repair and had recurrent urinary tract infections (UTI) during the preschool years. The patient was a twin B with preterm labor who was born at 36 weeks of gestation and had developmental language and cognitive delays and repetitive and compulsive-like behaviors, which led to receiving early intervention program in the preschool years. According to his twin brother, the patient had a habit of squeezing water into his urethra through condoms almost every day for years.

Focused physical examination revealed sacral tenderness, high anal tone, and tender prostate without fluctuation. Transabdominal sonography (Fig. 1A) demonstrated a $5.4 \times 5.9$ $\mathrm{cm}$ heterogeneous septated mass over the pelvic region, which was confirmed by computed tomography (CT) scan (Fig. 1B). His uroflow curve revealed staccato pattern (Fig. 1C). Intravenous ertapenem was prescribed for 2 weeks, and a follow-up abdominal CT scan after this treatment revealed resolution of the prostatic abscess (Fig. 2B). In addition, Lexapro was prescribed once daily for the repetitive behavior. At the 1-month follow-up, his urinalysis was clean, transabdominal sonography revealed no signs of prostatic abscess (Fig. 2A), and the uroflow curve was bell shaped (Fig. 2C). In addition, the patient also had fewer repetitive behaviors. 


\section{Discussion}

To our knowledge, this is the first case of a large prostatic abscess in an adolescent who was successfully treated with antibiotics only. Prostatic abscess usually affects middle-aged men at an estimated rate of $0.2 \%-0.5 \%{ }^{1}$ however, it could occur at any age. ${ }^{2}$ The common pathogens of prostatic abscess are E. coli and Klebsiella pneumonia, whereas atypical pathogens are often presented in severely immunocompromized patients. ${ }^{3}$ The clinical symptoms of prostatic abscess include dysuria, urgency, frequency, sense of incomplete emptying, and suprapubic or perineal pain. Some patients only have systemic symptoms, such as fever or malaise. ${ }^{1}$ Risk factors of prostatic abscess in adults include diabetes, chronic kidney disease, liver cirrhosis, liver abscess, human immunodeficiency virus infection, and acquired immune deficiency syndrome. Those who underwent chemotherapy, organ transplant, or previous genitourinary procedures also had a higher risk of prostatic abscess. ${ }^{1}$

Only 3 cases of prostatic abscess in adolescents have been reported to date (Table 1). Predisposing factors in these 3 patients were previous MRSA infection ${ }^{4}$ and chronic granulomatous disease. ${ }^{5}$ However, the most recent case had no identifiable risk factors. ${ }^{6}$ The possible risk factors of the presented case were the behavior of squeezing water into his urethra through condoms for masturbation and a history of recurrent UTIs. The repetitive forceful influx of contaminated water into the urethra may have caused prostate infection, which when not treated led to the formation of multilocular abscess.

Currently, there is no standard treatment for prostatic abscess. In the previous case reports of adolescents with prostatic abscess, all patients underwent drainage or transurethral unroofing of the prostatic abscess. The size of the abscess in the previous 3 cases was no $>3 \mathrm{~cm}$. Compared with this, the size of the abscess in our patient was the largest abscess reported to date $(5.9 \mathrm{~cm}$ in the greatest dimension on abdominal CT scans) and the patient responded well to antibiotic treatment only. Reports suggest that surgical treatment is optimal when the patient has a slow response to antibiotics. ${ }^{2,7}$ According to previous reports, antibiotics alone should only be used in stable patients with a small prostatic abscess $<1 \mathrm{~cm} .{ }^{1,8}$ Oshinomi et al concluded that antibiotics should be used in patients with diffuse type prostatic abscess and drainage or transurethral resection of the prostate was more suitable in patients with focal or multifocal type prostatic abscess. ${ }^{9}$ However, our report demonstrated that antibiotics alone as the first-line treatment are curative in an adolescent patient with prostatic abscess. There are 2 possible reasons to explain why our patient could be conservatively treated. First, the patient was diagnosed and treated quite early. Second, he did not have comorbidities, such as diabetes mellitus or other factors contributing to immunocompromized status, which were common in adult cases with prostatic abscess. Therefore, it is questionable whether large prostatic abscesses should all be treated by aspiration or surgical drainage as the first-line treatment. We believe that with adequate antibiotics and optimal patient selection, adolescents with prostatic abscess can be conservatively treated.

\section{Conclusion}

A large prostatic abscess in an adolescent should first be treated with conservative treatments. The early diagnosis of the disease, its potential risk factors, and early antibiotic intervention are essential for its successful treatment. 


\section{References}

1. Ackerman AL, Parameshwar PS, Anger JT. Diagnosis and treatment of patients with prostatic abscess in the post-antibiotic era. Int J Urol 2018;25:103-10

2. Wein AJ, Kavoussi LR, Partin AW, et al. Campbell-Walsh Urology. 4. 11ed 2016. p. 304-29.

3. Abdelmoteleb H, Rashed F, Hawary A. Management of prostate abscess in the absence of guidelines. Int Braz J Urol 2017;43:835-40.

4. Kiehl N, Kinsey S, Ramakrishnan V, et al. Pediatric prostatic abscess. Urology 2012;80:1364-5.

5. Agochukwu NQ, Rastinehad AR, Richter LA, et al. Prostatic abscess in a pediatric patient with chronic granulomatous disease: report of a unique case and review of the literature. J Pediatr Surg 2012;47:400-3.

6. Foster CE, Hulten KG, Janzen NK, et al. Pediatric Prostatic Abscess Caused by Methicillin-Susceptible Staphylococcus aureus. Pediatr Infect Dis J 2017;36:426-7.

7. Grabe M, Bartoletti R, Johansen TEB, et al. Guidelines on urological infections: European Association of Urology; 2015 Available from: http://www.uroweb.org.

8. Chou YH, Tiu CM, Liu JY, et al. Prostatic abscess: transrectal color Doppler ultrasonic diagnosis and minimally invasive therapeutic management. Ultrasound Med Biol 2004;30:719-24.

9. Oshinomi K, Matsui Y, Unoki T, et al. Treatment strategy for prostatic abscess: Eighteen cases' report and review of literature. Urol Sci. 2018;29:206-9. 


\section{Figures and Tables}

Fig. 1. (A) Abdominal sonography revealed a heterogeneous septated mass. (B) Contrastenhanced computed tomography scan of the abdomen and pelvis revealed prostatic abscess with multiple loculations (arrow). (C) Uroflow revealed staccato pattern.
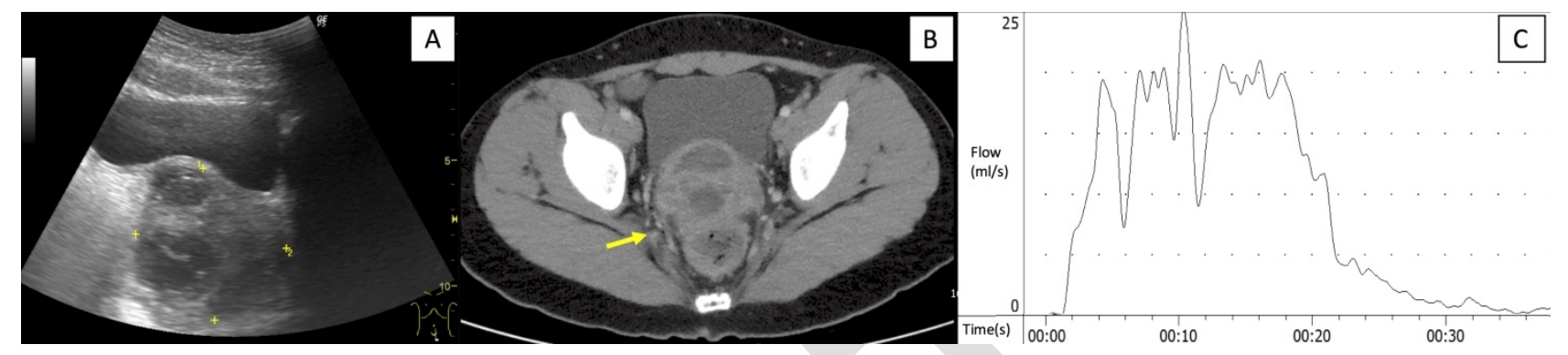

Fig. 2. (A \& B) Abdominal sonography and contrast-enhanced computed tomography scan of the abdomen and pelvis revealed almost complete resolution of the disease. $(\boldsymbol{C})$ Uroflow revealed bell-shaped curve.
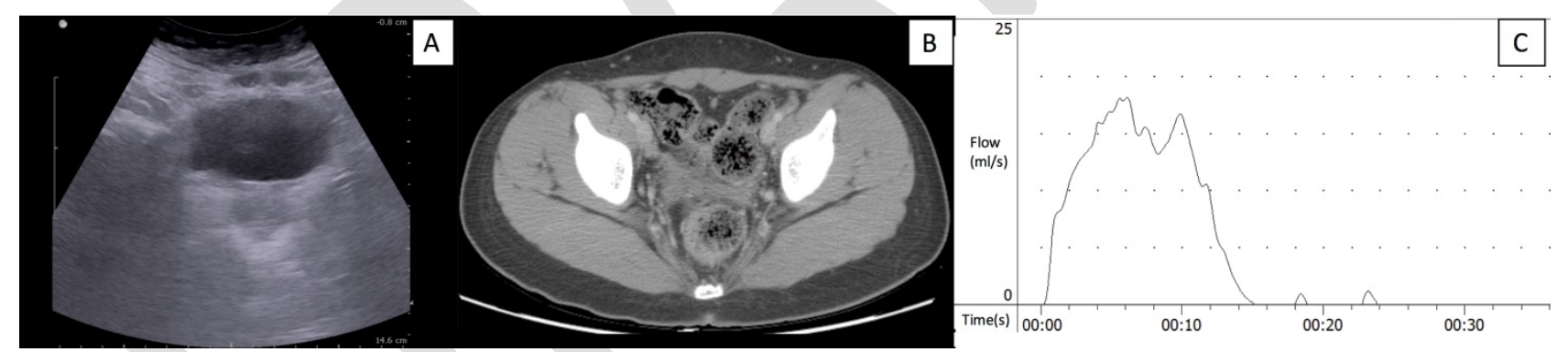
Table 1. Prostatic abscess in an adolescent

\begin{tabular}{|c|c|c|c|c|c|c|}
\hline Year & $\begin{array}{l}\text { Age } \\
\text { (years) }\end{array}$ & Risk factor & $\begin{array}{l}\text { Size of } \\
\text { prostatic } \\
\text { abscess } \\
(\mathrm{cm})\end{array}$ & Pathogen & Treatment & Outcome \\
\hline $2012^{4}$ & 15 & $\begin{array}{l}\text { Previous MRSA } \\
\text { infection }\end{array}$ & N/A & MRSA & $\begin{array}{c}\text { Transurethral } \\
\text { unroofing of prostatic } \\
\text { abscess }\end{array}$ & Cured \\
\hline $2012^{5}$ & 15 & X-linked CGD & 3 & Not found & $\begin{array}{l}\text { Transurethral } \\
\text { resection and } \\
\text { drainage of } \\
\text { prostatic abscess }\end{array}$ & Cured \\
\hline $2017^{6}$ & 11 & Nil & $1.9 \times 1.6$ & MSSA & $\begin{array}{c}\text { Percutaneous drainage } \\
\text { of abscess }\end{array}$ & Cured \\
\hline 2017 & 14 & $\begin{array}{c}\text { Repetitive } \\
\text { forceful influx of } \\
\text { contaminated } \\
\text { water into urethra }\end{array}$ & $5.4 \times 5.9$ & $\begin{array}{l}\text { Escherichia } \\
\text { coli }\end{array}$ & 14 days of antibiotics & Cured \\
\hline
\end{tabular}

CGD: chronic granulomatous disease; MSSA: methicillin-sensitive Staphylococcus aureus;

MRSA: methicillin-resistant Staphylococcus aureus; N/A: not available. 